03;04

\title{
Исследование стимулирования барьерным разрядом плазмохимических реакций
}

\author{
(C) В.Е. Маланичев ${ }^{1,2}$, М.В. Малашин ${ }^{1}$, С.И. Мошкунов ${ }^{1}$, \\ С.В. Небогаткин ${ }^{1}$, В.Ю. Хомич ${ }^{1}$, В.М. Шмелев ${ }^{2}$ \\ ${ }^{1}$ Институт электрофизики и электроэнергетики РАН, Санкт-Петербург \\ ${ }^{2}$ Институт химической фризики им. Н.Н. Семенова РАН, Москва \\ E-mail: mve.191@gmail.com
}

Поступило в Редакцию 22 декабря 2016 г.

Исследовано стимулирование барьерным разрядом реакций на примере реакции окисления метана кислородом воздуха до смеси монооксида углерода и водорода. В плазмохимическом реакторе экспериментально продемонстрирована возможность увеличения количества синтез-газа на выходе с помощью предварительной обработки исходной смеси плазмой. Исходной являлась смесь воздуха и метана при атмосферном давлении в соотношении $7: 1$. Состав выходного газа был измерен с помощью хроматографа. Показано, что при обработке разрядом количество синтез-газа на выходе из реактора увеличивается на $15 \%$. Селективность реакции по водороду и монооксиду углерода увеличилась на 3.2 и $6.5 \%$ соответственно.

DOI: 10.21883/PJTF.2017.10.44615.16613

Синтез-газ представляет собой смесь монооксида углерода и водорода. Его применяют в процессах синтеза метанола, гидроформилирования и в процессе Фишера-Тропша для синтеза синтетического топлива и масла $[1,2]$.

Существует несколько способов получения синтез-газа: паровая конверсия метана, углекислотная конверсия метана, парциальное (иногда называется частичное) окисление метана кислородом, газификация каменного угля. Также существуют технологии получения синтез-газа из биомассы и твердых бытовых отходов [1-5].

Было подсчитано, что при производстве метанола, аммиака и при синтезе Фишера-Тропша около 60-70\% от стоимости всего процесса связано с образованием синтез-газа [6]. Снижение затрат на производство синтез-газа будет иметь непосредственное влияние на общую стоимость этих процессов. 
В настоящей работе изучается получение синтез-газа путем парциального окисления метана (1), так как такой метод имеет ряд преимуществ, таких как экзотермическая реакция, в результате которой получаем смесь оксида углерода и молекулярного водорода в соотношении $1: 2$ соответственно (такое соотношение необходимо для дальнейших химических процессов), и отсутствие коррозии узлов установки (которая неизбежна при паровой конверсии):

$$
\mathrm{CH}_{4}+0.5 \mathrm{O}_{2} \rightarrow \mathrm{CO}+2 \mathrm{H}_{2} \text {. }
$$

В настоящее время для увеличения эффективности парциального окисления метана применяют родиевые или платиновые катализаторы [7-9]. В таких условиях достигается селективность реакции по водороду $\left(S_{\mathrm{H}_{2}}\right)$ от 25 до $85 \%$ и селективность по монооксиду углерода $\left(S_{\mathrm{CO}}\right)$ от 70 до $96 \%$. Недостатком такого метода является высокая цена катализаторов и их быстрая деградация.

Руководствуясь теоретическими предпосылками, можно утверждать, что с помощью предварительной обработки исходной смеси возможно повысить выход и селективность синтез-газа [10]. В различных плазмохимических реакторах (ПХР) были получены значения селективности по водороду $\left(S_{\mathrm{H}_{2}}\right)$ от 15 до $60 \%$ и оксиду углерода $\left(S_{\mathrm{CO}}\right)$ от 35 до $80 \%$ [11-13].

В экспериментах нами использовалась плазма барьерного разряда с диэлектриком (ДБР),так как она является неравновесной. В таком разряде проводить физико-химические реакции более эффективно, чем в равновесной плазме, так как активация исходного газа происходит с помощью электронов, обладающих высокими энергиями. Также в рассматриваемом устройстве обработанный газ, не успев вернуться в исходное состояние, попадает в зону горения по причине того, что зона обработки плазмой и зона горения близко расположены.

В экспериментах использовался ПХР с плоскопараллельной конфигурацией электродов (см. рисунок). Верхний электрод 2 был выполнен в виде стальной сетки диаметром $52 \mathrm{~mm}$, нижний, заземленный электрод 4 сплошной. Электроды разделял диэлектрик (выполненный из стекла) толщиной $2 \mathrm{~mm}$ и воздушный зазор 3 величиной $1.5 \mathrm{~mm}$. В реактор подавалась смесь воздуха и метана в соотношении 7:1. Суммарный расход газа составлял $6.91 / \mathrm{min}$. Исходный газ проходил предварительную обработку разрядом в области 3 и далее, проходя через сеточный электрод, попадал в зону горения 1. Инициация

Письма в ЖТФ, 2017, том 43, вып. 10 


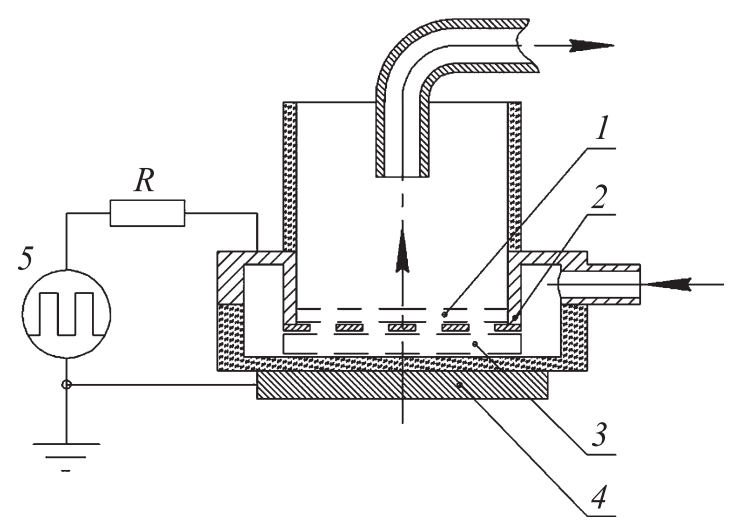

Экспериментальная установка: 1 - зона горения; $2-$ сеточный электрод; 3 - разрядный промежуток; 4 - заземленный электрод; 5 - высоковольтный источник; $R$ - токоограничивающий резистор.

горения производилась путем воспламенения смеси на выходе из реактора, далее фронт пламени перемещался к сеточному электроду 2 , и в дальнейшем самоподдерживающийся процесс горения происходил вблизи сеточного электрода. Химический состав выходного потока измерялся с помощью хроматографа марки М3700, который имел три параллельных аналитических канала, что позволяло одновременно анализировать все компоненты газа. Хроматограф был оснащен тремя детекторами: одним пламенно-ионизационным и двумя детекторами по теплопроводности. В системе использовались набивная колонка с молекулярными ситами $\mathrm{CaA}$, колонка с Porapak Q и капиллярная колонка HO-PLOT $\mathrm{Al}_{2} \mathrm{O}_{3} / \mathrm{KCL}$.

К сеточному электроду прикладывались прямоугольные высоковольтные импульсы с амплитудой $10.5 \mathrm{kV}$, длительностью $60 \mu \mathrm{s}$ с частотой $4 \mathrm{kHz}$. Импульсы формировались с помощью специального генератора $5[14,15]$.

Анализ состава выходного газа производился для трех различных режимов: окисление метана без предварительной обработки плазмой ДБР (режим 1); парциальное окисление метана с предварительной обработкой плазмой ДБР (режим 2); парциальное окисление метана плазмой ДБР без процесса горения (режим 3).

Письма в ЖТФ, 2017, том 43, вып. 10 
Результаты измерения состава газа и расчета селективностей

\begin{tabular}{c|c|c|c}
\hline $\begin{array}{c}\text { Компонент / } \\
\text { Селективность }\end{array}$ & Исходный состав газа & Режим 1 & Режим 2 \\
\hline $\mathrm{O}_{2}$, vol.\% & $17.5 \pm 0.1$ & $2.3 \pm 0.4$ & $2.2 \pm 0.6$ \\
$\mathrm{CH}_{4}$, vol.\% & $12.3 \pm 0.4$ & 0.0 & 0.0 \\
$\mathrm{CO}_{2}$, vol.\% & $0.1 \pm 0.1$ & $7.3 \pm 0.5$ & $6.7 \pm 0.3$ \\
$\mathrm{CO}$, vol.\% & 0.0 & $5.2 \pm 0.4$ & $6.0 \pm 0.4$ \\
$\mathrm{H}_{2}$, vol.\% & 0.0 & $5.5 \pm 0.4$ & $6.3 \pm 0.4$ \\
\hline $\mathrm{S}_{\mathrm{H}_{2}}, \%$ & - & $22.4 \pm 2.4$ & $25.6 \pm 2.5$ \\
$\mathrm{~S}_{\mathrm{CO}}, \%$ & - & $42.3 \pm 4.7$ & $48.8 \pm 4.8$
\end{tabular}

Селективность $\mathrm{H}_{2}$ и $\mathrm{CO}$ рассчитывалась как

$$
\begin{gathered}
S_{\mathrm{H}_{2}}=\frac{V_{\text {obt } . \mathrm{H}_{2}}}{2 V_{\text {conv. } \mathrm{CH}_{4}}} \cdot 100, \\
S_{\mathrm{CO}}=\frac{V_{\text {obt. } \mathrm{CO}}}{V_{\text {conv. } \mathrm{CH}_{4}}} \cdot 100 .
\end{gathered}
$$

В реакторе был реализован мультиканальный режим горения ДБР [16]. Характерное значение амплитуды пикового тока составляло $8 \mathrm{~A}$, энергия, вкладываемая в разряд, $3 \mathrm{~mJ}$. Значение средней мощности, вкладываемой в плазму, составляло $25 \mathrm{~W}$.

Результаты измерения состава газа и расчет селективностей представлены в таблице. В этой таблице не указан состав выходного газа в режиме 3 , так как различий между исходным газом и газом на выходе не было обнаружено.

Из таблицы видно, что в обоих режимах количество $\mathrm{CO}_{2}$ увеличивается по сравнению с исходным составом. Это указывает на присутствие реакции полного окисления метана

$$
\mathrm{CH}_{4}+2 \mathrm{O}_{2} \rightarrow \mathrm{CO}_{2}+2 \mathrm{H}_{2} \mathrm{O} \text {. }
$$

Также можно отметить, что, когда исходный газ предварительно обрабатывается плазмой, выход $\mathrm{CO}_{2}$ уменьшается на 0.6 vol.\%, а количество $\mathrm{CO}$ и $\mathrm{H}_{2}$ увеличивается на 1.8 vol.\% каждый. Расчет селективности

Письма в ЖТФ, 2017, том 43, вып. 10 
показал, что $S_{\mathrm{H}_{2}}, S_{\mathrm{CO}}$ при втором режиме возросли на 3.2 и $6.5 \%$ соответственно.

Принимая во внимание вышесказанное, можно сделать вывод, что после предварительной обработки исходного газа плазмой ДБР количество синтез-газа на выходе из ПХР увеличилось, что связано с активацией исходной смеси плазмой путем наработки химически активных частиц в газе.

Исследовалось стимулирование барьерным разрядом реакций на примере стимулирования реакции парциального окисления метана в ПХР. Рассматривалось три режима работы: когда предварительно исходный газ обрабатывается плазмой ДБР и далее поступает в зону горения, когда предварительно не обрабатывается и когда окисление происходило в плазме без процесса горения. В последнем случае выход синтез-газа не зафиксирован, но в режиме горения, когда газ предварительно был обработан плазмой, количество синтез-газа увеличилось по сравнению с режимом без предварительной обработки на $15 \%$. Селективность реакции по водороду и монооксиду углерода увеличилась на 3.2 и $6.5 \%$ соответственно.

Исследование выполнено при финансовой поддержке РФФИ в рамках научного проекта № 16-38-60194 ,мол_а_дк“.

\section{Список литературы}

[1] Bharadwaj S.S., Schmidt L.D. // Fuel Proc. Technol. 1995. V. 42. N 2. P 109.

[2] Satterfield C.N. Heterogeneous Catalysis in Industrial Practice. New York: McGraw-Hill, 1991.

[3] van den Oosterkamp P.F., van den Brink R.W. Synthesis Gas GenerationIndustrial. Wiley: Encyclopedia of Catalysis, 2010.

[4] Рутберг Ф.Г., Гончаренко Р.Б., Кумкова И.И., Сафронов А.А. // Известия Российской академии наук. Энергетика. 2015. № 4. С. 104.

[5] Рутберг Ф.Г., Братцев А.Н., Кузнецов В.А. и др. // Письма в ЖТФ. 2014. T. 40. B. 17. C. 1.

[6] Haggin J. // Chem. Eng. News. 1992. V. 70. N 17. P. 33.

[7] Neumann D., Veser G. // AIChE J. 2005. V. 51. N 1. P. 210

[8] Enger B.C., Lodeng R., Holmen A. // Appl. Catal. A: General. 2008. V. 346. N 1. P. 1.

[9] Lyubovsky M., Roychoudhury S., LaPierre R. // Catal. Lett. 2005. V. 99. N 3. P. 113. 
[10] Kado S., Urasaki K., Sekine Y., Fujimoto K. // Fuel. 2003. V. 82. N 11. P 1377.

[11] Hwang N., Cha M., Lee D. et al. // Proc. ISNTPT-6. 2008. P. 95.

[12] Nozaki T., Abe S., Moriyama S. et al. // Japan. J. Appl. Phys. 2015. V. 54. P. 1.

[13] Bie C.D., Dijk J., Bogaerts A. // J. Phys. Chem. C. 2015. V. 119. N 39. P. 22331.

[14] Малашин М.В., Мошкунов С.И., Хомич В.Ю. // Прикладная физика. 2010. № 5. C. 102.

[15] Khomich V.Yu., Malashin M.V., Moshkunov S.I. et al. // IEEE Transact. Plasma Sci. 2014. V. 42. N 10. P. 3314.

[16] Khomich V.Yu., Malanichev V.E., Malashin M.V., Moshkunov S.I. // IEEE Transact. Plasma Sci. 2016. V. 44. N 8. P. 1349.

2 Письма в ЖТФ, 2017, том 43, вып. 10 